\title{
Borgolte, Michael, Stiftungen in Christentum, Judentum und Islam vor der Moderne
}

\section{Olivier Richard}

\section{OpenEdition \\ Journals}

Édition électronique

URL : http://journals.openedition.org/ifha/1585

DOI : 10.4000/ifha.1585

ISSN : 2198-8943

Éditeur

IFRA - Institut franco-allemand (sciences historiques et sociales)

Référence électronique

Olivier Richard, «Borgolte, Michael, Stiftungen in Christentum, Judentum und Islam vor der Moderne », Revue de l'IFHA [En ligne], Date de recension, mis en ligne le 01 janvier 2008, consulté le 22 septembre 2020. URL : http://journals.openedition.org/ifha/1585 ; DOI : https://doi.org/10.4000/ifha.1585

Ce document a été généré automatiquement le 22 septembre 2020

(CIFHA 


\title{
Borgolte, Michael, Stiftungen in Christentum, Judentum und Islam vor der Moderne
}

\author{
Olivier Richard
}

1 Ce volume rassemblant les actes d'un colloque de Berlin de 2003 (dont une grosse moitié est en anglais), dirigé par le grand spécialiste des fondations médiévales, envisage ces dernières non pas sous leur aspect juridique, mais comme question d'histoire sociale et culturelle, conformément au virage pris dans leur étude depuis une trentaine d'années ; la nouveauté du projet réside dans sa dimension comparative. Le constat dressé par M.B. est la présence de fondations dans la plupart des cultures et des époques, pour peu qu'on choisisse une définition large : il y a fondation lorsqu'un fondateur donne des biens ou des revenus assis sur des biens pour assurer des prestations sur une longue durée. La réalisation de la volonté du fondateur par les institutions ou les personnes chargées de sa fondation assure la présence du fondateur parmi elles et les bénéficiaires de sa bonté. La fondation est donc vue comme fabrique de lien social entre vivants et défunts, mais aussi entre vivants, exécuteurs ou curateurs et bénéficiaires.

2 Deux contributions sont comparatives ; l'une présente les fondements théologiques des fondations - le poids des œuvres pies dans la recherche du salut dans le christianisme occidental et oriental, l'islam et le judaïsme (R. Lusiardi); l'autre, une communication de G. Baer de 1981 dont la mort de l'auteur l'année suivante avait empêché la publication, étudie, à partir du waqf islamique, les fondations comme institutions dans les sphères culturelles des religions déjà citées mais aussi au-delà, ainsi en Inde ou au Népal. Ce type de synthèses est bien sûr risqué, consistant nécessairement en une compilation imparfaite et les spécialistes de tel ou tel point y trouveront sans doute à redire, mais ces deux articles sont toutefois très utiles comme bases de discussion.

Les autres contributions se cantonnent à un contexte donné, l'Empire romain avant le triomphe du christianisme (S. Pickert), les awqāf islamiques au Moyen Âge (J. Pahlitzsch et A. Sabra pour l'Égypte des Mamelouks, A. M. Carballeria-Debasa pour 
l'Andalousie musulmane), dans le monde ottoman (S. Faroqhi), les fondations et fondateurs à Byzance (J. Thomas, p. Horden, D. C. Stathakopoulos) ou en Russie ancienne (L. Steindorff), enfin dans les communautés juives médiévales d'Égypte (M. R. Cohen) ou hispanique et allemande (J. D. Galinsky). Un seul article traite de l'Occident médiéval, plus précisément des relations entre les fondations pieuses et la cristallisation du pouvoir politique dans les villes allemandes médiévales (B. Scheller).

4 Au total, la comparaison ne convainc pas encore totalement. Trop souvent les auteurs invoquent le caractère " universel » des fondations, faute de pouvoir procéder à une vraie analyse (voir p. 271 la citation de M. C. Regmi, « Systems such as the gu.thī [la « fondation " au Népal] have existed in some form or other in almost all parts of the world, irrespective of the predominant religion sponsoring them. The origins of such systems are probably as old as settled agriculture and organized religion themselves »). L'ensemble souffre, d'autre part, d'un état de la recherche très variable entre les espaces étudiés, l'Occident chrétien ayant donné lieu à un nombre beaucoup plus grand d'études, appuyées sur des sources plus riches ou plus facilement accessibles. Ainsi la question des transferts entre les différentes religions, ou aires géographiques et culturelles, n'est pas abordée. Mais comment le reprocher à ce volume, qui est une des premières tentatives d'une approche comparative ? L'ouvrage excède d'ailleurs de loin le simple constat des différences et des similitudes.

5 La comparaison entre les différentes contributions permet de voir que par-delà les fondements théologiques - croyance ou non en un jugement individuel, reconnaissance ou non des œuvres comme moyen d'obtenir le salut, poids accordé aux intercessions des vivants - les fondations mais aussi l'ensemble des pratiques mémorielles dépendent beaucoup du contexte politique ou social dans lequel elles sont mises en œuvre. Ainsi, alors que les juifs d'Allemagne et de France, à la fin du Moyen Âge, cherchent à obtenir en échange de leurs œuvres pies des prières de leur communauté - à l'imitation des chrétiens parmi qui ils vivent -, ceux de l'Espagne du XIIIe s., eux aussi auteurs de fondations, ne recherchent pas l'intercession ; or justement les pratiques mémorielles sont moins flamboyantes et moins répandues chez les chrétiens d'Espagne, sans parler des musulmans. L'ouvrage montre aussi, pour donner un second exemple, qu'en Égypte mamelouke comme à Byzance ou au Népal, la fondation est un moyen d'empêcher les confiscations ou aliénations de biens et ainsi, paradoxalement, de perpétuer la domination familiale sur un bien.

6 Finalement, ce colloque n'est qu'une étape sur la voie vers une comparaison entre tous les systèmes de « fondations ", mais elle est très importante.

Olivier Richard (Université de Haute-Alsace, Mulhouse) 